\title{
O PROCESSO DE RECUPERAÇÃO DO DEPENDENTE DE CRACK
}

\section{The recovery process of crack dependent}

Claudius Cesar Bandeira Martins ${ }^{1}$, Ricardo de Lima de Meloㄹ, Elisete Rossato Rick², José Otávio Feltrin², Maria Tereza Soratto ${ }^{3}$

${ }^{1}$ Enfermeiro - UNISUL - Universidade do Sul de Santa Catarina - Araranguá - SC

- Brasil.

2 Enfermeira (o) - Mestrado em Saúde Coletiva - Professora (o) do Curso de Enfermagem UNISUL - Universidade do Sul de Santa Catarina - Araranguá - SC Brasil.

${ }^{3}$ Enfermeira - Mestrado em Educação - Professora do Curso de Enfermagem UNISUL - Universidade do Sul de Santa Catarina - Araranguá - SC - Brasil.

\section{Endereço para correspondência:}

Maria Tereza Soratto

R. Dom Joaquim Domingos de Oliveira, 50. Apt 301. Ed. Jatobá. Centro. Criciúma SC. CEP: 88.801-230.

Email: guiga@engeplus.com.br; guiga@unesc.net 


\title{
Resumo
}

O crack atualmente é considerado um grave problema de saúde pública e uma epidemia social, dependência química causadora de riscos, violência e vulnerabilidade social. Esta pesquisa teve como objetivo identificar de que forma ocorre o Processo de Recuperação do Dependente de Crack. Foi realizada na UBS Bom Pastor no município de Araranguá, Santa Catarina. Trata-se de uma pesquisa qualitativa, descritiva-exploratória e de campo. Foram entrevistados sete pacientes em tratamento de dependência em crack. Os dados foram coletados através de entrevista semiestruturada e analisados a partir da categorização dos dados. As dificuldades para a readaptação social, familiar e em relação ao tratamento sentidas pelos pacientes foram relacionadas à discriminação; desemprego e conflitos familiares. A assistência da equipe multiprofissional de saúde é organizada através de consulta médica, acompanhamento com psicólogo, exames e tratamento medicamentoso, internações, grupos de apoio e palestras. O tratamento para a dependência química depende de vários fatores inter-relacionados: a vontade do usuário de permanecer em abstinência, equipe multiprofissional capacitada para a abordagem dos dependentes e familiares, suporte familiar, fé e espiritualidade, além de uma rede de serviços que atue como suporte ao tratamento.

Palavras-chave: Crack; Dependência; Transtornos Relacionados ao Uso de Substâncias; Centros de Tratamento de Abuso de Substâncias.

\begin{abstract}
The crack is now considered a serious public health problem and a social epidemic, causing addiction risks, violence and social vulnerability. This research aimed to identify how the process occurs Recovery Dependent Crack. Was held at Good Shepherd UBS Araranguá in the municipality of Santa Catarina. This is an exploratory - descriptive qualitative research and field. Seven patients were interviewed in the treatment of addiction to crack cocaine. Data were collected through semi - structured and analyzed from data categorization interview. The difficulties in social, family and in relation to the treatment experienced by rehabilitation patients were related to discrimination, unemployment and family conflicts. The assistance of the multidisciplinary health care team is organized
\end{abstract}




\section{Artigo Original \\ Saúde e Processos Psicossociais}

through medical consultation, monitoring with a psychologist, diagnostic tests and medical treatment, hospitalization, support groups and lectures. Treatment for drug addiction depends on several interrelated factors: the willingness of the user to remain abstinent; able to address the multidisciplinary team and family dependents, family support, faith and spirituality, and a network of services that act as supportive care.

Keywords: Crack; Dependency; Substance-Related Disorders; Substance Abuse Treatment Centers.

\section{INTRODUÇÃO}

O consumo do crack atualmente é considerado um problema social que cresce a cada dia. A droga crack surgiu nos EUA na década de 1980. No Brasil, chegou no início da década de 1990, disseminando-se inicialmente no estado de São Paulo1. O crack é um potente estimulante do sistema nervoso central com alto potencial de dependência, merecendo atenção por causa dos riscos associados ao padrão de uso compulsivo². A questão do uso de crack no Brasil já tomou uma grande proporção, sendo considerado um grave problema de saúde pública ${ }^{2-4}$.

A sensação de urgência por crack tem incentivado o usuário à realização de atividades ilícitas, intensificando o processo de marginalização social e os riscos à sua liberdade e integridade física, psíquica e moral ${ }^{5}$. É frequente o envolvimento em atividades violentas e ilícitas como roubos, assaltos, tráfico e atividades sexuais de risco para obtenção de dinheiro ou droga ${ }^{2,4}$. Consideradas em conjunto, tais atitudes têm interferido negativamente sobre a saúde e funcionamento social do usuário de crack de forma a marginalizá-lo, tanto no contexto micro (como nas redes de uso) quanto macrossocial (comunidades e sistemas de serviço) ${ }^{5}$.

Em função dos efeitos do crack, considera-se raro que os usuários consumam a droga uma única vez, prolongando o uso até que se esgotem física, psíquica ou financeiramente ${ }^{5}$. Desta forma o crack traz, comprovadamente, prejuízos para a vida dos usuários, seus familiares e para a sociedade em geral ${ }^{3}$.

Em virtude dos efeitos estimulantes e prazerosos, aliados aos baixos custos da comercialização ilegal, o crack rapidamente se espalhou pelo território brasileiro, 


\section{Artigo Original \\ Saúde e Processos Psicossociais}

nas mais diferentes classes sociais, podendo ser percebido no cotidiano como um grave problema público que apresenta proporções ainda pouco conhecidas e de grande impacto familiar e social. Tem-se, assim, de um lado, o usuário de crack (e sua família) em situação de vulnerabilidade e fragilidade e, de outro, a necessidade de um tratamento complexo com abordagem multiprofissional e interdisciplinar, em serviços ainda pouco estruturados e experientes no atendimento ao dependente químico ${ }^{6}$.

Diante das dificuldades enfrentadas pelo Dependente Químico (DQ) e a necessidade de readaptação social e familiar surgiram inquietações dos pesquisadores referentes à temática: Como ocorre a readaptação do $D Q$ em crack após o tratamento e alta? Como a família enfrenta o processo de readaptação do DQ? Como evitar a reincidência do usuário de crack? De que forma a equipe multiprofissional pode auxiliar na readaptação social e familiar do DQ?

O crack atualmente é considerado uma epidemia social, a Dependência envolve riscos, violência e vulnerabilidade social. O usuário possui maior risco de desenvolver doenças associadas ao uso de drogas, como HIV, Tuberculose, Pneumonias, além de doenças mentais associadas ao risco de suicídio. O DQ sofre marginalização social, familiar e das equipes de saúde que não se encontram adequadamente preparadas para lidar com o usuário.

Consideradas em conjunto, as implicações associadas ao uso de crack consistem em importante problema à saúde pública, sendo necessário o desenvolvimento de programas de intervenção e políticas públicas ao seu controle ${ }^{5}$. De acordo com Freire et al., ${ }^{3}$ o delineamento de programas de prevenção e de tratamento se torna crucial para que se conheça a realidade da população atendida, a fim de se construírem ações condizentes com tal contexto.

Desta forma considera-se essencial conhecer como o dependente se adapta à sociedade e com a família durante o tratamento, e que estratégias poderiam ser utilizadas pela equipe multidisciplinar para evitar a reincidência do usuário de crack. Conhecer a realidade através da vivência do próprio usuário pode oportunizar uma melhor compreensão do fenômeno do uso do crack e subsidiar estratégias de cuidado de enfermagem.

A partir destas reflexões, teve-se como objetivo da pesquisa identificar de que forma ocorre o Processo de Recuperação do Dependente de Crack. 
O estudo caracterizou-se como qualitativo, descritivo, exploratório e de campo. Foi realizado no Ambulatório para $D Q$ da Unidade Central de um município no Estado de Santa Catarina, Brasil, nos meses de outubro a novembro de 2013. Realizou-se entrevista semiestruturada com 7 Dependentes de Crack. Como Critérios de Inclusão utilizou-se 0 dependente de crack em tratamento no Ambulatório para dependentes químicos e aceitação para participar da pesquisa a partir da assinatura do Termo de Consentimento Livre e Esclarecido, segundo os preceitos éticos da Resolução 466/127. A análise de dados foi realizada através da análise de conteúdo, a partir da categorização de dados. "Um dos procedimentos mais úteis para a investigação qualitativa é a formulação e organização dos dados em categorias". Categoria refere-se a um conceito que abrange elementos ou aspectos com características comuns ou que se relacionam entre $\mathrm{si}$, sendo estabelecidas para classificar os eventos. Categorizar é agrupar elementos, ideias ou expressões em torno de um conceito ${ }^{8}$.

Para preservar o sigilo decorrente das entrevistas realizadas com os sujeitos pesquisados, de acordo com as diretrizes e normas regulamentadoras da Res. 466/12 que envolvem pesquisa com Seres Humanos e Grupos Vulneráveis, utilizouse a letra "P" (significado de Paciente), seguido do seu respectivo número para referenciar os dependentes de Crack pesquisados.

A pesquisa foi aprovada pelo Comitê de Ética em Pesquisa da UNISUL pelo Projeto no 414846/2013.

\section{RESULTADOS E DISCUSSÃO}

\section{Caracterização do Perfil dos Dependentes de Crack}

Em relação ao perfil dos dependentes, quatro são do sexo masculino e três do sexo feminino. A escolaridade é bem variada, desde a $1^{\text {a }}$ série até o superior incompleto. Também se considera os dependentes de crack jovens, com faixa etária variando de 18 a 42 anos. Quanto ao tempo de uso, foi de 2 anos a 10 anos. O tempo de tratamento dos pacientes é de um mês a 5 anos. 


\section{Artigo Original}

\section{Saúde e Processos Psicossociais}

Destaca-se que a maioria dos pacientes em tratamento no Ambulatório é desempregada; somente a P3 é do lar e P4 trabalha na prostituição. Quanto ao estado civil, somente o P5 é casado; o restante dos pacientes é solteiro (a). O perfil do usuário de crack foi identificado como homem, jovem, de baixa escolaridade e sem vínculos empregatícios formais ${ }^{5,9}$.

\section{Utilização de Drogas Associadas}

Todos os dependentes em tratamento no ambulatório relataram que utilizavam maconha e álcool com o crack; cinco (05 - P2; P4; P5; P6; P7) utilizavam tabaco; três (03 - P2; P4; P5) cocaína e um (01 - P4) chá de cogumelo, LSD, êxtase, lança perfume.

Geralmente o usuário de crack não consome apenas um tipo de droga, ele faz o uso associado delas afim de reduzir alguns efeitos indesejáveis. Algumas drogas levam à utilização de outras como complemento das primeiras. Por exemplo, o consumo de crack está ligado ao consumo de cigarro, já que aquele necessita de cinzas para ser queimado e, dessa forma, fumado. A maconha é outra droga muito utilizada, já que seu consumo possibilita uma atenuação dos efeitos indesejáveis, como a paranoia provocada pela cocaína e, em especial, pelo crack. O álcool é outra droga que se associa ao consumo de cocaína e crack, sob a alegação de uma atenuação de efeitos indesejáveis e um prolongamento dos efeitos prazerosos. Essa afirmação está de acordo com o perfil farmacológico da cocaína que, em presença de álcool, tem seu metabolismo alterado com a formação de cocaetileno, o qual tem um efeito muito semelhante à cocaína, prolongando dessa forma os efeitos dessa droga ${ }^{10}$.

Conforme Zeni e Araujo ${ }^{11}$, os dependentes de crack geralmente fazem o uso de drogas associadas, sendo dependentes de tabaco (100\%), de maconha $(93,9 \%)$, de álcool $(57,6 \%)$ e de solventes $(24,2 \%)$. Este fator pode produzir efeitos clínicos e comportamentais adversos, cumulativos e sinérgicos, através da interação entre as substâncias no organismo do usuário, podendo afetar no resultado do tratamento. 
Artigo Original

Saúde e Processos Psicossociais

Motivos e Circunstâncias que Levaram ao Uso da Droga

Como motivos para o uso do crack os pacientes relacionaram à morte de pessoa próxima e ao luto (03 - P1; P5; P6); curiosidade (03 - P2; P3; P7); amizades (01 - P7) e grande oferta da droga (01 - P4).

A morte e o luto envolvido na perda foram relatados como motivo que levou ao uso da droga pelos pacientes P1, P5 e P6. Segundo as falas:

"Foi perder meu padrasto eu gostava muito dele era como meu pai." (P1).

"Quando morreu um primo meu, que era um irmão pra mim, isso me abalou muito, a gente se identificava mesmo, saia juntos, foi o que me levou a usar crack." (P5).

"Foi perder meu filho e falta de vergonha na minha cara mesmo." (P6).

A intensidade do consumo do crack parece estar diretamente relacionada com o risco de desenvolvimento do transtorno depressivo ${ }^{21}$. Em uma pesquisa desenvolvida em São Paulo, jovens que usaram álcool, tabaco e drogas ilícitas relataram ter mais problemas familiares do que aqueles que não usaram nenhuma substância ${ }^{15}$.

Destaca-se que a curiosidade para usar o crack foi destacado como motivo para a utilização da droga pelos pacientes P2, P3 e P7; além das amizades, segundo o relado do $\mathrm{P} 7$.

"Curiosidade." (P2) e (P3).

"As amizades e a curiosidade." (P7).

Neto, Fraga e Ramos ${ }^{12}$ afirmam que a curiosidade e os amigos são os principais motivos para experimentar as drogas. A curiosidade foi o fator de risco mais frequente manifestado pelos adolescentes para o primeiro uso de drogas ${ }^{13}$.

Em estudo dos fatores relacionados ao uso de drogas pelos adolescentes ${ }^{14}$, estão relacionados aos locais que frequentam, tais como: casa de amigos $(42,9 \%)$, 
Artigo Original

Saúde e Processos Psicossociais

boates e bares (34,3\%). As drogas consumidas pelos adolescentes foram maconha $(60 \%)$, crack $(20 \%)$, solventes $(11,4 \%)$ e outras $(17,6 \%)$.

A grande oferta, facilitando o acesso à droga, foi relatado como motivo do uso do crack pelo paciente P4:

"Gostava da cocaína e estava difícil de encontrar na época, e tinha uma grande oferta de pedra na cidade e eu cansei de perder dinheiro com a cocaína ruim que tinha e passei a fumar crack." (P4).

Em pesquisa entre os adolescentes que usaram drogas ilícitas ${ }^{15}$, a idade foi o fator de maior associação, seguido por discutir frequentemente com os pais, passar a maior parte do tempo livre com os amigos, sentir que os pais não se importam ou cuidam deles e ter membro da família que foi preso.

\section{A busca do tratamento}

Os motivos para buscar o tratamento são principalmente a família (06 - P1 a P6); força de vontade (01 - P5) e ver-se diante da morte (01 - P7). A família, sendo a motivação principal da busca de tratamentos pelos pacientes, foi destacada nas falas de P1 a P6; além da própria força de vontade necessária para lutar contra a droga e vencer esta batalha citada na fala do P5.

"O sofrimento da minha mãe." (P1).

"Minha familia, especialmente minha mãe." (P2).

"Certamente os meus filhos." (P3).

"Meus filhos." (P4).

"Minha esposa, minha família ambas evangélicas e minha força de querer mudar conquistar algo de concreto como bens, filhos e etc." (P5).

"Meu filho." (P6). 
A presença da família é muito importante durante todo o processo de tratamento e é fundamental também na etapa da reinserção social do ex-usuário de crack. O restabelecimento das relações sociais positivas está diretamente relacionado à manutenção das transformações. Um dos primeiros passos que deve se dar para o processo de reinserção social é evitar o isolamento do usuário. É uma ilusão achar que só a internação vai resolver o problema. $\mathrm{Na}$ realidade, a desintoxicação do paciente é só uma parte do tratamento, porque o mais importante é a reinserção social do indivíduo novamente na sociedade. É fundamental que a família reconheça que ele está em um processo de tratamento de dependência química, que compreenda as dificuldades e ofereça apoio para que ele possa reconstruir sua vida social. No tratamento os familiares e amigos devem apoiar o dependente, se possível com ajuda profissional. O principal risco para um ex-usuário é se sentir solitário, desvalorizado e sem a confiança das pessoas próximas ${ }^{1}$.

Podemos observar em uma pesquisa ${ }^{9}$ que dentre os usuários que afirmaram bom relacionamento com os pais, foram identificados depoimentos que remetem a sentimentos de afeto e apoio da família em relação ao problema das drogas.

A visualização da própria morte em decorrência do uso do crack foi um dos motivos que levou o paciente P7 a buscar tratamento.

"É que eu quase morri cinco vezes já, é que eu apago e levanto louco após usar pedra, eu comecei a me esforçar para não usar mais e buscar tratamento." (P7).

Episódios definidos pelos usuários como overdose foram aqueles relacionados com algum tipo de atendimento hospitalar, ou seja, efeitos percebidos como extremamente graves. Alguns usuários deixaram claro que têm medo dessa complicação, outros sequer acreditam nessa possibilidade ${ }^{2}$.

O sucesso de qualquer tipo de tratamento para uma dependência química passa, em grande parte, pela vontade do usuário de se manter afastado da droga (abstinência). Sem isso, nenhuma proposta terapêutica funcionará. Entretanto, há que se considerar o fenômeno da comorbidade, ou seja, a coexistência no mesmo indivíduo de outros transtornos mentais (depressão, psicoses, dependências de álcool, transtornos graves de personalidade) que, caso não sejam tratados 
Artigo Original

Saúde e Processos Psicossociais

concomitantemente, podem comprometer a recuperação. Um diagnóstico adequado permitirá traçar uma abordagem terapêutica mais eficaz, que esteja ajustada às características do paciente ${ }^{1}$.

\section{Motivação para vencer a luta contra o Crack}

O que motiva atualmente os pacientes para vencer a luta contra o Crack é em primeiro lugar as pessoas significativas e importantes representando a família, amigos e o casamento (06 - P1 a P6); seguido da própria força de vontade, decisão de mudar e sair da depressão, autoestima e honra (03 - P4; P5; P7) e a igreja (01 P6).

Os relatos nas falas são representativos da importância do suporte familiar, das pessoas significativas e dos amigos para os dependentes conseguirem ter forças para enfrentar o crack.

"O apoio da minha mãe está sendo fundamental para minha recuperação." (P1).

"Minha familia, especialmente minha mãe." (P2).

"Meus filhos." (P3).

A família se constitui socialmente em uma unidade primordial no âmbito da construção, formação e desenvolvimento dos indivíduos que a compõem, transmitindo às gerações valores, regras, costumes, ideias, além de modelos e padrões de comportamentos, inclusive hábitos nocivos à saúde. A existência de vínculos relacionais saudáveis entre os indivíduos e as famílias, como delimitação das responsabilidades, apoio e afeto familiar, é apontada como fator protetor quanto ao uso de drogas ${ }^{9}$.

O paciente P6 ressaltou, além da família e os amigos, como motivo atual para vencer a luta contra o Crack, a igreja.

"Meu filho, a Igreja Pentecostal que eu estou frequentando, meus amigos antigos." (P6). 
Artigo Original

Saúde e Processos Psicossociais

Afirma Backes et al. ${ }^{16}$ que a prática religiosa pode ser uma poderosa fonte de conforto, esperança e significado, especialmente no enfrentamento de doenças crônicas, tanto físicas quanto mentais, portanto, pode contribuir significativamente na luta contra o crack.

Destaca-se na fala do paciente P4 e P5 a necessidade da decisão de mudar. $\mathrm{Na}$ fala do P5 o resgate da autoestima e do casamento, honra e o controle da depressão, além do relato do paciente $\mathrm{P} 7$ que ressalta a importância da busca da cura de si mesmo.

"Meu casamento, autoestima de quando se para de usar, a minha saída da depressão, necessidade de adquirir respeito das pessoas novamente, ser uma pessoa honrada." (P5).

"Estou cansada de ver pessoas que gostam de mim, sofrer por minha causa, minha vida parou, deixei de fazer planos na minha vida e decidi mudar." (P4).

"Mais é por mim mesmo, tenho que fazer por mim." (P7).

Características pessoais como autoestima preservada e perspectiva de futuro e, finalmente, aspectos culturais como crença e prática de uma religião podem ser razões de não-uso e afastamento do dependente do consumo de drogas ${ }^{17}$.

\section{As Dificuldades para a Readaptação Social, Familiar e em relação ao Tratamento}

As dificuldades para a readaptação social, familiar e em relação ao tratamento sentidas pelos pacientes foram relacionadas à: discriminação (06 - P1; P2; P3; P4; P6; P7); desemprego e falta de chance (02 - P1 e P6) e as brigas e conflitos familiares (01 - P5).

As falas são representativas da discriminação e preconceito relatado por todos os pacientes em recuperação e o desemprego sentido nos relatos dos pacientes. 
"Não conseguia trabalhar mais, parei de frequentar lugares como festas, bares e qualquer lugar com muita gente, sinto que sou discriminado por ser usuário." (P1).

"Preconceito, discriminação porque, as pessoas acham que todo drogado é vagabundo, algumas pessoas da minha família me criticam muito." (P2).

"O preconceito dos meus vizinhos e da sociedade por eu ser usuária." (P3).

"O que mais me incomoda é o preconceito com meus filhos pelo fato de eu ser dependente e ex-presidiária." (P4).

"A falta de chance na sociedade por ser ex-usuária de crack." (P6).

"O preconceito, algumas pessoas te tratam diferente por ser usuário, porque acham que você vai roubar elas para usar a droga, e o local que eu moro, na minha rua tem muita boca de pedra." (P7).

A estigmatização social de um indivíduo ${ }^{18}$ pode apresentar profundas consequências negativas. O estigma social pode causar forte impacto à vida para a pessoa estigmatizada, pois envolve aspectos amplos à vida dos sujeitos, assim como a formação e a transformação da identidade social desvalorizada num dado contexto social. Indivíduos estigmatizados são tidos como "imperfeitos", "comprometidos" e de alguma forma teriam um atributo em algumas situações mais extremas desumanizadas. Por causa dessas características, a estigmatização apresenta profundas consequências negativas, e mesmo patológicas, para a personalidade, resultando em estratégias e enfrentamento ou fuga de algumas situações que podem se tornar prejudiciais aos indivíduos. Levando em consideração o forte substrato sociocultural do estigma, o contexto tem, portanto, um forte papel em relação ao nível de consequências para o indivíduo estigmatizado.

As consequências negativas de certa forma podem ser indiretas, como a dificuldade de acesso a cuidados na rede de saúde, educação, emprego, moradia, e assim o torna cada vez mais a margem da sociedade e sem expectativas de mudança de sua vida ${ }^{18}$. 
Artigo Original

Saúde e Processos Psicossociais

Os conflitos no relacionamento intrafamiliar foram relatados pelo paciente P5 como dificuldade para a readaptação social, familiar e em relação ao tratamento.

"As brigas com minha família porque sou muito alterado, acho que devido ao longo tempo do uso da droga." (P5).

É possível visualizar os rompimentos dos relacionamentos afetivos como uma dimensão relevante que está associada à ação do $\operatorname{crack}^{19}$. Família, amigos e suas relações amorosas não suportam a nova rotina vivida a partir da inserção do crack em suas vidas. A ausência de um verdadeiro e significativo sentido existencial contribui para a deturpação do respeito, da confiança e da credibilidade que thes eram atribuídos antes da dependência ${ }^{19}$.

É muito difícil ter uma relação conjugal estável com usuários de crack, pois a ocorrência de conflitos relacionais com o seu parceiro(a) pelo uso da droga, caracterizada por desentendimentos e constantes cobranças para cessar o uso da droga e buscar tratamento, são frequentemente evidenciadas ${ }^{9}$.

\section{As Facilidades para a Readaptação Social, Familiar e em relação ao Tratamento}

As facilidades para a readaptação social, familiar e em relação ao tratamento citadas pelos pacientes foi: Tratamento no ambulatório com acompanhamento da equipe multiprofissional e com uso de medicamentos (04 - P3; P4; P5; P7), suporte da família (03 - P1; P2; P7), igreja, os relacionamentos interpessoais, a música e os filmes (01 - P6).

O acompanhamento do Ambulatório, através da equipe multiprofissional e do acompanhamento psicológico, o uso de medicamentos para controlar a ansiedade e a fissura foi destacado pelos pacientes como essencial para a readaptação social, familiar e em relação ao tratamento.

"Os remédios, porque facilitam no tratamento diminuindo minha ansiedade." (P3). 
"O programa da Unidade, os horários, o atendimento dos profissionais é de ótima qualidade, a facilidade do acesso ao tratamento fora de clínicas de recuperação, e os remédios." (P4).

"O acompanhamento do psicólogo me ajuda muito, por ser uma pessoa que entende o que eu estou passando, e os medicamentos que auxiliam diminuindo minha fissura do uso da droga, este acompanhamento aqui na unidade me ajuda muito mesmo." (P5).

"Minha família me facilita muito, as visitas ao psicólogo me facilitam a compreender o que estou passando e o que estou sentindo hoje, gosto de ver TV também para me distrair um pouco." (P7).

Devido à crescente demanda de usuários de drogas no município, a Secretaria de Saúde implantou o Ambulatório para Dependentes Químicos. O programa tem como objetivo trabalhar a problemática do uso das drogas bem como os demais conflitos que ela causa no usuário e no âmbito familiar. O ambulatório de DQ possui uma equipe de profissionais composta por médico psiquiatra, 02 psicólogos, enfermeira e um assistente social. O programa oferece todo o suporte ao usuário, através de consulta médica, acompanhamento psicológico, terapias individuais e em grupo, e, dependendo do caso do paciente, o encaminhamento para internação. A implantação do programa veio da necessidade do município possuir um serviço organizado para tratar especificamente o problema de drogas ${ }^{20}$.

Essa abordagem tem sido cada vez mais valorizada dentro do processo de tratamento dos usuários, uma vez que parece aumentar a adesão aos tratamentos subsequentes $\mathrm{A}$ desintoxicação é uma abordagem de curta duração, de duas a quatro semanas, realizada tanto em ambiente ambulatorial/domiciliar quanto de internação ${ }^{21}$.

O craving (ou fissura) pode ser definido como um intenso desejo de utilizar uma específica substância, o qual engloba também, para alguns autores, a intenção de realizar esse desejo, a antecipação dos efeitos reforçadores associados ao uso e o alívio do afeto negativo e dos sintomas relacionados à abstinência. $O$ craving deve 


\section{Artigo Original \\ Saúde e Processos Psicossociais}

ser considerado uma variável importante a ser observada no tratamento da dependência química, pois deixa o dependente vulnerável ao abuso de drogas e pode levá-lo à recaída e ao abandono terapêutico, mesmo diante da vontade convicta de manter-se abstinente e/ou depois de grandes períodos de abstinência. No caso específico da dependência de crack, o craving é descrito como incontrolável pelos usuários, levando-os, em sua maioria, ao uso compulsivo, com padrão diário de consumo e por até nove dias contínuos, sendo só finalizado quando é atingido o esgotamento físico, psíquico e/ou financeiro. Diante dessa realidade, o manejo do craving adquire grande importância para a eficácia do tratamento de dependentes de crack $^{11}$.

Chaves et al. ${ }^{22}$ define fissura como um forte impulso para utilizar uma droga. É considerada ponto crítico para o desenvolvimento da dependência do uso de drogas e de recaídas após período de abstinência. Quanto maior a satisfação do sujeito com a sua própria vida, menor a possibilidade de sucumbir à fissura ${ }^{11}$.

A família novamente foi citada pelos pacientes P7, P1 e P2 como facilidades para a readaptação social, familiar e em relação ao tratamento, conforme relato.

"A satisfação de voltar a frequentar os lugares que eu frequentava antes de usar a droga, estar presente com a minha família, na verdade a minha família é o que mais facilita o meu tratamento aqui na Unidade." (P1).

"Minha família é a que mais facilita meu tratamento, eles tem fé que eu vou me recuperar, principalmente minha mãe e minha tia, gosto de sair para passear com elas." (P2).

A igreja, os relacionamentos interpessoais, a música e os filmes foram considerados como facilidade para a readaptação social, familiar e em relação ao tratamento pelo paciente $\mathrm{P} 6$.

"A igreja, meus namorados, minhas músicas e meus filmes evangélicos, facilitam meu tratamento." (P6). 
Desviar o pensamento e ocupar-se com outras formas de sentir prazer como a prática de esportes ou de uma religião podem ser estratégias muito eficazes para substituição do pensamento fixo no crack. Estes tipos de atividades estimulam a zona de recompensa do cérebro, similarmente ao próprio mecanismo de ação do crack.

Dormir também é um método eficaz e geralmente induzido pelo uso de medicamentos. Alguns pacientes relatam que a maconha pode reduzir a fissura de crack. Afastar-se do local e dos amigos de consumo é uma forma de não permitir que a fissura se desenvolva, também. Em alguns casos, os próprios usuários procuraram a internação, pois restringir a própria liberdade impossibilita o contato com o contexto de uso, impedindo o desenvolvimento da fissura ${ }^{11}$.

\section{A Assistência da Equipe Multidisciplinar de Saúde}

Em relação à assistência da equipe multiprofissional de saúde, os dependentes de crack recebem: consulta médica, acompanhamento com psicólogo, exames e tratamento medicamentoso (07 - P1 a P7), internações (03 - P2; P5; P7), grupos de apoio (02 - P4; P5) e palestras (01 - P6).

Segue as falas representativas da assistência recebida da Equipe Multidisciplinar de Saúde, sendo que todos os pacientes recebem consulta médica, acompanhamento com psicólogo, exames e tratamento medicamentoso.

"Consulta com médico, exames, acompanhamento com 0 psicólogo e psiquiatra uma vez por semana e medicamentos." (P1).

"Encaminhamento para internações, consulta com médico, exames, acompanhamento com o psicólogo uma vez por semana e medicamentos." (P2).

"Consulta com médico, exames, acompanhamento com 0 psicólogo uma vez por semana e medicamentos." (P3).

"Consulta com médico, exames, acompanhamento com 0 psicólogo uma vez por semana, medicamentos e grupo de apoio nas sextas-feiras." (P4). 
"Consulta com médico, exames, acompanhamento com o psicólogo uma vez por semana, medicamentos, já me ofereceram internação e grupo de ajuda, mas eu acho que não preciso." (P5).

"Consulta com médico, exames, acompanhamento com o psicólogo uma vez por semana, medicamentos e palestras." (P6).

"Encaminhamento para internações, consulta com médico, exames, acompanhamento com o psicólogo uma vez por semana e medicamentos." (P7).

Para Kessler e Pechansky ${ }^{23}$, o tratamento do crack faz parte de um complexo sistema e deve receber uma abordagem multidisciplinar. O uso de psicofármacos costuma auxiliar, apesar de ainda não haver uma medicação considerada eficaz para o uso de crack. A estratégia que demonstra maior resultado passa por uma estrutura de tratamento de longo prazo, que contempla uma internação inicial em ambiente psiquiátrico localizado em hospital geral e se estende para um modelo de atendimento baseado em comunidades terapêuticas fechadas ou com alto grau de intensidade de tratamento, também por longos períodos frequentemente de 6 meses a 1 ano. "A rede familiar e social tem um papel preponderante na aderência ao tratamento, devido à baixa motivação dos pacientes, e no monitoramento por longo prazo durante o período de manutenção da abstinência"23.

Podemos ressaltar ${ }^{24}$ que a participação em grupos de apoio promove a troca de experiências com outras pessoas com problemas semelhantes, essa oportunidade de compartilhar problemas entre si é uma forma de se sentirem incluídas no grupo, isto proporciona a manutenção da autoestima e confiança, ajudando a superar dificuldades. 
Artigo Original

Saúde e Processos Psicossociais

Palavras a um dependente de crack que ainda não procurou ajuda e tratamento

Todos os pacientes diriam a um dependente de crack para procurar ajuda, sem ajuda é difícil, procurar enquanto dá tempo, evitar velhos lugares, mudar hábitos e costumes.

"Que procure, porque isso não é vida." (P1).

"Que procure enquanto dá tempo". (P2).

"Que procure, pois há salvação." (P3).

"Já mandei três pra cá, e falaria para que eles procurassem porque ajuda a pessoa a se livrar do crack." (P4).

"Que procurasse ajuda, porque sem ajuda é difícil, quanto mais ajuda melhor, quanto mais se envolver com as pessoas melhor." (P5).

"Para evitar velhos lugares, mudar hábitos e costumes e procurar ajuda". (P6).

"Para procurar ajuda porque o resto eles já sabem, tá na droga é porque quer." (P7).

O crack suscita preocupação por dúvidas sobre a efetividade dos planos de tratamento e pela dificuldade de adequação da oferta de serviços à expansão da demanda, além de repercussões clínicas significativas entre seus usuários, como episódios psicóticos, déficit cognitivo, alterações do humor e do comportamento e pneumopatias. A atenção necessária à população usuária de crack, que se multiplica em curto espaço de tempo, demanda flexibilidade e capacidade de adaptação dos serviços de saúde, além de maiores investimentos na área ${ }^{25}$.

Considera-se que o usuário que já enfrentou a luta contra as drogas, a desintoxicação, a ansiedade e desespero dos momentos de fissura e que hoje tornou-se um ex-dependente é a melhor pessoa para conseguir ajudar os dependentes, pois sua própria história de luta e força para sair das drogas pode ser uma motivação para quem encontra-se neste caminho. 
Artigo Original

Saúde e Processos Psicossociais

Palavras sobre o Crack a uma pessoa que nunca utilizou a droga

O crack é ida sem volta, viagem sem volta, caminho sem volta, é triste, terrível, não experimente, é o que os pacientes diriam às pessoas que nunca usaram crack.

"Que não utiliza-se, não chegasse nem perto, é ida sem volta." (P1).

"Que não use porque é uma viagem sem volta." (P2).

"Que nunca use, caminho sem volta." (P3).

"Nunca experimente". (P4).

"Não experimente de maneira nenhuma." (P5).

"Dar os parabéns, que nunca experimente, que é coisa mais triste que tem, é terrível, a gente vira bicho." (P6).

"Para não usar, eu falo para as pessoas que eu conheço que usam outras drogas para não experimentar essa desgraça nunca." (P7).

Valorizar o entendimento da dinâmica de vida do usuário de crack, assim como as questões que os permeiam - tráfico, polícia, prostituição -, tem papel essencial no fomento de políticas públicas para assistência a essa população². Sendo que a informação para redução de danos ou abstinência pode advir do próprio usuário de crack, detentor do conhecimento, apontando a necessidade de estudos detalhados a respeito ${ }^{5}$.

\section{Sugestões sobre o processo de tratamento do dependente de Crack}

Houve sugestões referentes ao tratamento ambulatorial: aumento do número de consultas com psicólogo (P1 e P3), acompanhamento domiciliar (P3), não faltar remédios $(\mathrm{P} 4)$.

"Aumentar o número de vezes de consultas com o psicólogo." (P1). 
"No caso uma extensão do tratamento até as casas, mais acompanhamento do psicólogo." (P3).

"Que não falte nunca mais remédios, só isso." (P4).

Interessante a sugestão do paciente $\mathrm{P} 5$, que foca na divulgação do programa e tratamento, para os dependentes saberem onde buscar ajuda e a prevenção ao uso de drogas.

P5: "Que eles mostrem o tratamento como é feito para a população, isso pode interessar quem quer se livrar, porque existem muitas pessoas que querem sair, mas não sabem onde buscar ajuda, estão sujos, malcheirosos em trapos e fica difícil obter ajuda desta forma, acho que devem ser feitas campanhas e que o governo devia investir mais em prevenção do uso, do que no tratamento em si, e que divulguem mais o tratamento.

Os pacientes P6 e P7 estão satisfeitos com o tratamento ambulatorial e o paciente $\mathrm{P} 2$ não teve sugestões.

"Estou satisfeita com o tratamento e não mudaria nada, ele é bem completo." (P6).

"No momento acho que não falta nada, tem tudo que nós precisamos para o tratamento." (P7).

"Não tenho sugestões". (P2).

O crack é uma droga de difícil tratamento - particularmente se levarmos em consideração os modelos atualmente propostos para atendimento de drogas no Brasil. "O tratamento deve ser multidisciplinar e dividido em diversas etapas através de um modelo complexo de característica biopsicossocial, enfocando especialmente as estratégias de prevenção de recaída", devendo incluir aspectos individuais, familiares e sociais, dirigidos aos problemas associados a $D Q$, como problemas psiquiátricos, legais e de emprego ${ }^{23}$. 


\section{CONCLUSÕES}

Quando questionados sobre os motivos que os levaram a usar o crack, os pacientes relataram a curiosidade, a morte de pessoas próximas, seguidas das amizades e da grande oferta da droga. Isto reafirma dados da literatura que trazem a curiosidade como o maior motivo do uso do crack. Devemos focar então em esclarecer os jovens que devem superar essa curiosidade, ainda mais quando se trata dessa droga que é tão devastadora.

Ficou evidente que o motivo que mais incentiva os usuários a buscar o tratamento é a família (mães, filhos, esposas), seguido da própria vontade e experiência próximo a morte/overdose. Acreditamos que o sucesso do tratamento depende em grande parte do apoio e acompanhamento que o dependente recebe de seus familiares e equipe multidisciplinar. A força de vontade é um fator fundamental para a busca de resultados positivos no tratamento.

As maiores dificuldades para a readaptação em relação ao tratamento citadas pelos pacientes foram relacionadas à discriminação, seguida do desemprego e as brigas e conflitos familiares. Já as facilidades para a readaptação em relação ao tratamento citadas pelos pacientes foram o tratamento no ambulatório com acompanhamento da equipe multiprofissional e com uso de medicamentos, suporte da família, igreja, os relacionamentos interpessoais, a música e os filmes.

Esperávamos que a família seria citada diversas vezes durante as entrevistas, mas o número de vezes superou nossas expectativas. O paciente deve desviar seus pensamentos e ocupar-se com outras formas de sentir prazer, como a prática de esportes ou de uma religião. Este tipo atividades estimulam a zona de recompensa do cérebro, similarmente ao próprio mecanismo de ação do crack no cérebro. Quanto maior a satisfação com a sua própria vida, menores são as possibilidades de recaídas.

É fundamental realizar o acompanhamento nesse tipo de caso para evitar as recaídas. Um dos fatores que mais auxiliam na prevenção das recaídas é o tratamento medicamentoso, que contribui na diminuição da sensação da fissura, ou seja, da vontade de usar a droga.

Com certeza o crack causa a desestruturação familiar, pois evidentemente conviver com a rotina vivida pelo usuário de crack é realmente um desafio para as 


\section{Artigo Original}

\section{Saúde e Processos Psicossociais}

famílias, o descontrole emocional que o crack causa em seus usuários pode gerar situações de risco.

O consumo de crack no Brasil é um assunto que merece mais atenção do Ministério da Saúde e da sociedade, pois tal droga permeia todas as classes sociais e, como pôde-se verificar neste estudo, tem um poder forte de destruição e desestruturação do usuário e, consequentemente, de suas famílias, causando um prejuízo social e econômico enorme para o país. No nosso ponto de vista devemos estender as pesquisas na prevenção do consumo de crack pelos jovens, evitando o primeiro contato com o crack, porque tratar a dependência do paciente é muito mais difícil, leva muito mais tempo, causa maior ônus e necessita maiores recursos do que se focarmos nossos esforços na prevenção.

A pesquisa nos permitiu compreender que o apoio da família e um acolhimento de boa qualidade da equipe multidisciplinar contribui significativamente para acelerar o processo de recuperação do paciente. A mensagem que todos os pacientes querem deixar a uma pessoa que nunca utilizou o crack é que esta droga é um caminho sem volta, muito triste e, a mais importante, nunca experimente o crack de forma alguma.

Sugerimos aos próximos pesquisadores do tema que se aprofundem nas investigações do perfil da família dos usuários, aprimorando o estudo referente ao nível de entendimento que a família tem sobre a dependência ser uma patologia e do seu papel como a base do tratamento.

\section{REFERÊNCIAS}

1. Brasil. Crack é possível vencer. Brasília: Ministério da Saúde; 2013.

2. Ribeiro LA, Sanchez ZM, Nappo SA. Estratégias desenvolvidas por usuários de crack para lidar com os riscos decorrentes do consumo da droga. J Bras Psiquiatr. 2010;59:210-8.

3. Freire SD, Santos PL, Bortolini M, Moraes JFD, Oliveira MS. Intensidade de uso de crack de acordo com a classe econômica de usuários internados na cidade de Porto Alegre/Brasil. J Bras Psiquiatr. 2012;61(4):221-6.

4. Scheffer M, Pasa GG, Almeida RMM. Dependência de álcool, cocaína e crack e transtornos psiquiátricos. Psic Teor e Pesq. 2010;26:533-41. 


\section{Artigo Original}

\section{Saúde e Processos Psicossociais}

5. Oliveira LGd, Nappo SA. Caracterização da cultura de crack na cidade de São Paulo: padrão de uso controlado. Rev Saude Publica. 2008;42:664-71.

6. Rodrigues DS, Backes DS, Freitas HMB, Zamberlan C, Gelhen MH, Colomé JS. Conhecimentos produzidos acerca do crack: uma incursão nas dissertações e teses brasileiras. Ciênc saúde coletiva. 2012;17:1247-58.

7. Brasil. Resolução oㅡ 466, de 12 de dezembro de 2012. Brasília: Conselho Nacional de Saúde; 2012.

8. Leopardi MT. Teoria e método em assistência de enfermagem. 2 ed. Florianópolis: Soldasoft; 2006.

9. Seleghim MR, Marangoni SR, Marcon SS, Oliveira MLF. Family ties of crack cocaine users cared for in a psychiatric emergency department. Rev Latino-Am Enfermagem. 2011;19:1163-70.

10. Sanchez ZvdM, Nappo SA. Seqüência de drogas consumidas por usuários de crack e fatores interferentes. Rev Saúde Pública. 2002;36:420-30.

11. Zeni TC, Araujo RB. Relação entre o craving por tabaco e o craving por crack em pacientes internados para desintoxicação. J bras psiquiatr. 2011;60:28-33.

12. Neto C, Fraga S, Ramos E. Consumo de substâncias ilícitas por adolescentes portugueses. Rev Saúde Pública. 2012;46:808-15.

13. Jinez LJ, Souza JRM, Pillon SC. Drug use and risk factors among secondary students. Rev Latino-Am Enfermagem. 2009;17:246-52.

14. Monteiro CFS, Araújo TME, Sousa CMM, Martins MdCC, Silva LLL. Adolescentes e o uso de drogas ilícitas: um estudo transversal. Rev enferm UERJ. 2012;20(3):344-8.

15. Malbergier A, Cardoso LRD, Amaral RA. Uso de substâncias na adolescência e problemas familiares. Cad Saúde Pública. 2012;28:678-88.

16. Backes DS, Backes MS, Medeiros HMF, Siqueira DF, Pereira SB, Dalcin CB, et al. Oficinas de espiritualidade: alternativa de cuidado para o tratamento integral de dependentes químicos. Revista da Escola de Enfermagem da USP. 2012;46:1254-9.

17. Sanchez ZM, Oliveira LG, Ribeiro LA, Nappo SA. O papel da informação como medida preventiva ao uso de drogas entre jovens em situação de risco. Ciênc saúde coletiva. 2010;15:699-708.

18. Ronzani TM, Furtado EF. Estigma social sobre o uso de álcool. $\mathrm{J}$ bras psiquiatr. 2010;59:326-32. 


\section{Artigo Original}

\section{Saúde e Processos Psicossociais}

19. Branco FMFC, Sousa MNP, Brito NCC, Rocha VLPO, Medeiros JM, Silva Junior FJG, et al. Compulsão, criminalidade, destruição e perdas: o significado do crack para os usuários. Enferm foco. 2012; 3(4):174-7.

20. Araranguá PMD. Secretaria de Saúde implanta ambulatório para dependentes químicos, 2013.: Secretaria de Saúde; 2013.

21. Marques ACPR, Ribeiro ML, Larnjeira RR, Andrada NC. Abuso e dependência: crack. Rev Assoc Med Bras. 2012;58:138-40.

22. Chaves TV, Sanchez ZM, Ribeiro LA, Nappo SA. Fissura por crack: comportamentos e estratégias de controle de usuários e ex-usuários. Rev Saúde Pública. 2011;45(6):1168-75.

23. Kessler F, Pechansky F. Uma visão psiquiátrica sobre o fenômeno do crack na atualidade. Rev psiquiatr Rio Gd Sul. 2008;30(2):96-8.

24. Alvarez SQ, Gomes GC, Oliveira AMN, Xavier DM. Grupo de apoio/suporte como estratégia de cuidado: importância para familiares de usuários de drogas. Revista Gaúcha de Enfermagem. 2012;33:102-8.

25. Horta RL, Esswein GC, Horta CL. Percepção de profissionais de saúde de CAPS I quanto a demandas relativas ao consumo de crack. Ciênc saúde coletiva. 2013;18(4):1099-108. 